\title{
In vivo Toxicity Investigation of Magnesium Oxide Nanoparticles in Rat for Environmental and Biomedical Applications
}

\author{
Nafiseh Mazaheri ${ }^{1}$, Nooshin Naghsh ${ }^{2,}$, Akbar Karimi ${ }^{1}$, Hossein Salavati ${ }^{3}$ \\ ${ }^{1}$ Department of Biology, Payame Noor University, Tehran, Iran \\ ${ }^{2}$ Department of Biology, Falavarjan Branch, Islamic Azad University, Isfahan, Iran \\ ${ }^{3}$ Department of Chemistry, Payame Noor University, Tehran, Iran \\ *Corresponding author: Nooshin Naghsh, Department of Biology, Falavarjan Branch, Islamic Azad University, Isfahan, Iran. Tel/Fax: +98-3137420134; \\ E-mail: naghsh@iaufala.ac.ir
}

Background: Magnesium oxide nanoparticles are characterized with a wide variety of applications and are massproduced throughout the world. However, questions remain regarding their safety. There has been paucity of toxicology research on their side effects, especially under in vivo conditions.

Objectives: The present paper aims at evaluating the toxicity of administering 10-15 $\mathrm{nm}$ magnesium oxide nanoparticles to Wistar rat under in vivo conditions. In addition, hematology, biochemistry, and histopathology of the rats are examined at various concentrations $\left(62.5-125-250-500 \mu \mathrm{g} \cdot \mathrm{mL}^{-1}\right)$ over 28 -days period.

Materials and Methods: In this study, 35 male Wistar rats were randomly divided into five groups, comprising one control group and four experimental groups, assigned to various doses of $\mathrm{MgO}$ nanoparticles by intraperitoneal injection. Eventually, blood samples were collected, and all animals were sacrificed for liver and kidney tissue investigation.

Results: The findings showed that high concentrations of Magnesium oxide nanoparticles (250 and $500 \mu \mathrm{g} . \mathrm{mL}^{-1}$ ) significantly increased white blood cells, red blood cells, hemoglobin, and hematocrit compared with the control group $(\mathrm{P}<0.05)$. Moreover, the nanoparticles elevated the levels of aspartate aminotransferase and alkaline phosphatase, whereas no significant difference in levels of alanine aminotransferase, gamma-glutamyl transpeptidase, urea, and creatinine were recorded in comparison with the control group $(\mathrm{P}<0.05)$. Histopathological examinations in the rat's liver showed proliferation of bile ductules, congestion in some regions of the liver sinusoids, and apoptotic cells (probably) in high-dose groups, but no histological changes were found in the kidney functions.

Conclusions: The results from the present study showed that the magnesium oxide nanoparticles in concentrations lower than $250 \mu \mathrm{g} . \mathrm{mL}^{-1}$ are safe for desired applications.

Keywords: in vivo; Magnesium Oxide; Toxicity

\section{Background}

Nanoparticles are miniscule materials (with at least one dimension less than $100 \mathrm{~nm}$ ) with unique properties, which make them suitable for novel applications. These attributes make them very attractive for commercial and medical developments (1). In recent years, the breakthroughs in nanotechnology have been accompanied with inorganic and organic nano-sized particles with growing applications to be used as modifier in industrial, medicine, therapeutics, synthetic textiles, and food packaging (2). Moreover, nanoparticles are expected to play a crucial role in water purification (3). Now, the rapid increase in world's population and shortage in fresh water demand appropriate, cost-effective, and rapid wastewater treatment techniques (4). By nanotechnology, water and wastewater can be treated not only to deal with main challenges of present treatment technology, but also to provide new treatment potentials, which in turn allows economic exploitations of unconventional water sources as a water supply (5).

As Sawai et al. pointed out, the moisture absorptions on the $\mathrm{MgO}$ nanoparticle surfaces, which forms a thin water layer around the particles, is a possible antibacterial mechanism. The local $\mathrm{pH}$ of the mentioned water layer can be greater than its equilibrium value under solution sets. When the nanoparticles are faced with bacteria, the high $\mathrm{pH}$ in that water layer could damage the membrane, resulting in cells death (6).

Given the unique properties of these particles, nanotechnology is also being applied in medical 
sciences (7). Recently, the initiative methods as per development of nanoparticle drugs have emerged in cancer treatment. Such particles offer controlled drug delivery, enhance permeability, and tumor specific targeting. In addition, nano-drugs cope with carcinogenic cells, enter them in an easy manner and, at the same time, have little side impacts on normal cells (8). The most important characteristics of these drugs are particle size, molecular weight, $\mathrm{pH}$, ionic strength, monomer concentration, and surface charge among others (9). At the same time, potentially nanoparticles have great contribution in diagnosis and imaging of brain tumors (10).

In medicine, $\mathrm{MgO}$ is used for the alleviation of heartburn, stomach sore, and for bone regeneration (11, 12). Nowadays, $\mathrm{MgO}$ nanoparticles are applied in tumor inhibition (13) and additionally, have remarkable potential as an antimicrobial agent (14). Other experimental results revealed the possible utility of $\mathrm{MgO}$ nanoparticles in the treatment of cancer, including Nano-cryosurgery and hyperthermia (15).

The applications of $\mathrm{MgO}$ nanoparticles and also the issues on its feasible toxicity are increasing (16). Unfortunately, there is a paucity of knowledge about the effect of the prolonged exposure to nanoparticles on human health and the environment. Before their large scale production and application in diverse fields, the impact of nanoparticles on health and environment merits more assessment $(17,18)$. Hence, estimating the cost/benefits ratio for utilizing nanoparticles in technological or medical procedures is of great importance.

The nanomaterial toxicity such as nanoparticles, quantum dots, nanotubes, and nanowires has been declared in the past few years (19-24). In this respect, various studies dealt with the toxicity of $\mathrm{MgO}$ nanoparticles. Lai et al. showed that treatment of human astrocytoma (astrocytes-like) U87 cells with $\mathrm{MgO}$ nanoparticles for $48 \mathrm{~h}$ did not significantly decrease their survival until the concentrations were higher than $50 \mu \mathrm{g} \cdot \mathrm{mL}^{-1}(25)$. Additionally, the cytotoxicity and neurotoxicity of $\mathrm{MgO}$ nanoparticles on SH-SY5Y cell line have also been investigated, and the results showed that $\mathrm{MgO}$ nanoparticles are not toxic in concentration ranges from $1 \mathrm{nM}$ to $1 \mathrm{mM}$ for 24,48 , and $72 \mathrm{~h}$ to both undifferentiated and differentiated SH-SY5Y cells. MTS method was used for cell viability (16).

These reports were mainly based on in vitro studies. It seems that in vitro cultures cannot provide significant data on the response of the physiological system under study (26). Consequently, studying the in vivo toxicity of $\mathrm{MgO}$ nanoparticles is very useful.

\section{Objectives}

There are few toxicological investigations of $\mathrm{MgO}$ nanoparticles in animal models. On this basis, the present research attempts to shed lights on in vivo toxicity of $10-15 \mathrm{~nm} \mathrm{MgO}$ nanoparticles under various concentrations $\left(62.5-500 \mu \mathrm{g} \cdot \mathrm{mL}^{-1}\right)$ for 28 days. Here, animals' hematology, biochemistry, and histopathology were characterized.

The outcome of this in vivo research will determine which concentration of $\mathrm{MgO}$ nanoparticles has no poisonous effect and would be appropriate for various applications

\section{Materials and Methods}

\subsection{Nanoparticles Characterization}

A stock suspension of $\mathrm{MgO}$ nanoparticles (1000 $\mu \mathrm{g} . \mathrm{mL}$ ${ }^{1)}$ was obtained from Neutrino Co. At first, characterization of the synthesized $\mathrm{MgO}$ nanoparticles was performed using transmission electron microscopy and X-ray diffraction analysis. Then, the $\mathrm{MgO}$ suspension was diluted by the distilled water. The various concentrations of these particles were obtained through a serial reducing of $1000 \mu \mathrm{g} \cdot \mathrm{mL}^{-1}$ by $1 \times$ Time, $2 \times$ Time, $3 \times$ Time, and final $4 \times$ Time to get 500,250 , 125 , and $62.5 \mu \mathrm{g} \cdot \mathrm{mL}^{-1}$, respectively.

\subsection{Experimental Design}

The study was conducted on 10 weeks age male Wistar rat, weighing 200-250 g, housed in polycarbonate cages an ambient temperature of $22 \pm 2^{\circ} \mathrm{C}$ with $12 \mathrm{~h}$-light and $12 \mathrm{~h}$-dark cycle. Animals were obtained from Darou Pakhsh Co. and given food and water ad libitum. All the experiments on animals were performed based on the guidelines of the institutional animal ethics committee. In this study, 35 rat were randomly divided into five groups (seven in each group) comprising one control group and four experimental groups assigned to various doses of $\mathrm{MgO}$ nanoparticles. Administration of the rats was performed using intraperitoneal injection. Each rat of group 2 to 5 received $1 \mathrm{~mL}$ of $\mathrm{MgO}$ nanoparticles solution at doses of $62.5 \mu \mathrm{g} \cdot \mathrm{mL}^{-1}, 125 \mu \mathrm{g} \cdot \mathrm{mL}^{-1}, 250$ $\mu \mathrm{g} \cdot \mathrm{mL}^{-1}$, and $500 \mu \mathrm{g} \cdot \mathrm{mL}^{-1}$, respectively (every other day). The control group rats were treated with citrate buffer alone. At the end of 28 days treatment, all the rats of the five groups were starved overnight and sacrificed after injection of $\mathrm{MgO}$ nanoparticles to determine the toxicity through examination of hematological, biochemical and histological analysis.

\subsection{Hematological and Biochemical Analysis}

28 days after treatment, blood samples were collected by intra-cardiac puncture following anesthesia with ketamine $100 \mathrm{mg} \cdot \mathrm{kg}^{-1}$ (Rotexmedica Co., Germany) and xylazine $10 \mathrm{mg} \cdot \mathrm{kg}^{-1}$ (Alfasan Co., Holland) (27).

For hematological analysis, blood was immediately collected in EDTA coated vials and hematologic toxicity was determined by the use of automated hematological analyzer (Sysmex Cell Counter Model K-1000). Hematological parameters examined in this study included white blood cells (WBC), red blood cells (RBC), hematocrit (HCT), platelet count (PLT), hemoglobin $(\mathrm{Hb})$ levels, mean corpuscular hemoglobin 
$(\mathrm{MCH})$, mean corpuscular hemoglobin concentration (MCHC), and mean corpuscular volume (MCV).

For estimation of serum biochemical analysis, blood was placed in a clotted vial. The serum was obtained by centrifugation of the whole blood at $3000 \mathrm{rpm}$ for 15 min to an automated analyzer (Hitachi 912 Chemistry Analyzer). Liver function was dealt with based on the serum levels of aspartate aminotransferase (AST), alanine aminotransferase (ALT), alkaline phosphatase (ALP), and $\gamma$-glutamyl transpeptidase (GGT).

Nephrotoxicity was determined by urea (UREA) and creatinine (CREA). The level of these biochemical parameters was measured by means of quantitative diagnostic kits with photometric method (Pars Azmun Co., Tehran, Iran).

\subsection{Histopathology}

After the treatment for 28 days, the histological analysis was performed by examining the morphological changes induced by $\mathrm{MgO}$ nanoparticles, over the liver and kidney. These organs were collected and fixed with a $10 \%$ formalin, embedded in paraffin, and cut into $5-\mu \mathrm{m}-$ thick sections.

The fixed sections were stained for analysis using hematoxylin and eosin ( $\mathrm{H}$ and $\mathrm{E})$ staining. The sections were examined under binocular microscope (Olympus $\mathrm{CH}-2$, Tokyo, Japan), and photomicrographs of the fixed organs were obtained.

3.5. Statistical Analyses of Data

Results are presented as mean \pm standard deviation. Data analysis was performed by one-way analysis of variance (ANOVA), followed by Tukey HSD test for multiple comparisons. The level of significance was set at $\mathrm{P}<0.05$.

\section{Results}

\subsection{Characterization of $\mathrm{MgO}$ Nanoparticles}

The morphology and size of the biologically synthesized $\mathrm{MgO}$ nanoparticles were determined using Transmission electron microscopy (model EM 208 Philips). The images clearly illustrated that the average size of the particles was found to be approximately 10 $15 \mathrm{~nm}$ and spherical in shape, as shown in Figure 1.

The XRD pattern obtained presented 5 intense peaks in the whole spectrum of $2 \theta$ values ranging from 30 to 80 . The diffraction peaks at $2 \theta$ values of $36.94^{\circ}, 42.90^{\circ}$, $62.30^{\circ}, 74.67^{\circ}$ and $78.61^{\circ}$, corresponding to 111,200 , 220,311 and 222 planes, respectively, for $\mathrm{MgO}$ based on the X-ray diffraction (XRD) analysis using a Philips PW $1710 \mathrm{X}$-ray powder diffractometer, as shown in Figure 2.

\subsection{Hematology Results}

The important step for toxicity detection is assessment of standard hematological parameters, including determination of white blood cells (WBC), red blood cells (RBC), hematocrit (HCT), platele count (PLT), hemoglobin $(\mathrm{Hb})$ levels, mean corpuscular hemoglobin
$(\mathrm{MCH})$, mean corpuscular hemoglobin concentration (MCHC), and mean corpuscular volume (MCV). Concentration-dependent hematology results are presented in Table 1.

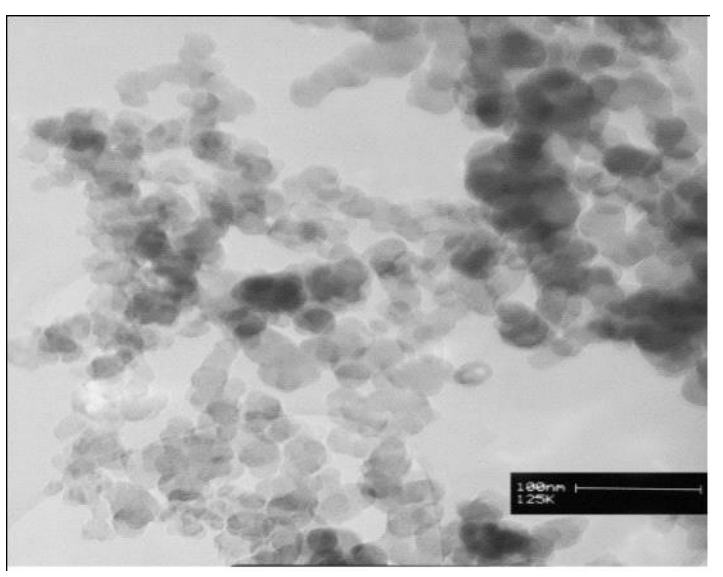

Figure 1. TEM images of the resulting $\mathrm{MgO}$ nanoparticles. The images clearly illustrated that the average size of the particles was found to be approximately $10-15 \mathrm{~nm}$ and spherical in shape.

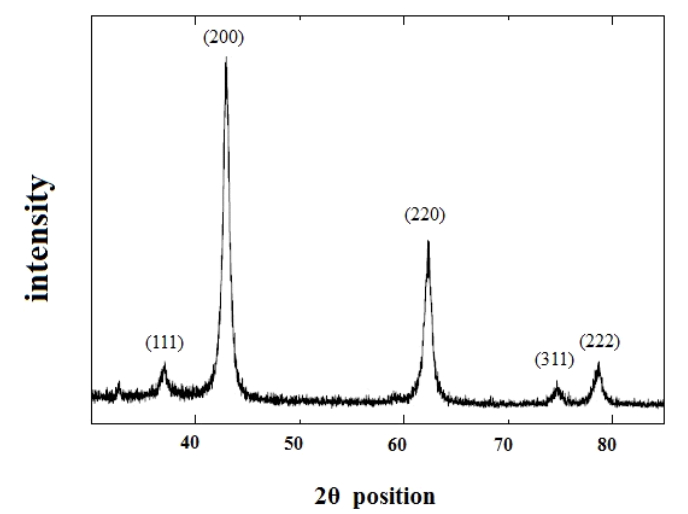

Figure 2. The $\mathrm{XRD}$ pattern of the resulting $\mathrm{MgO}$ nanoparticles presented 5 intense peaks in the whole spectrum of $2 \theta$ Values ranging from 30 to 80 . The diffraction peaks at $2 \theta$ values of $36.94 \circ, 42.90 \circ$, $62.30^{\circ}, 74.67^{\circ}$ and $78.61^{\circ}$, corresponding to $111,200,220,311$ and 222 planes, respectively.

We observed that white blood cells significantly increase at $\mathrm{MgO}$ nanoparticles doses of 250 and $500 \mu \mathrm{g} \cdot \mathrm{mL}^{-1}$, respectively $(\mathrm{P}<0.05)$.

This information demonstrated a concentrationdependent trend correlated with treatment. Meanwhile, amounts of hemoglobin, red blood cells, and hematocrit were significantly increased with the injection of $\mathrm{MgO}$ nanoparticles at a dosage of $500 \mu \mathrm{g} \cdot \mathrm{mL}^{-1}(\mathrm{P}<0.05)$.

\subsection{Serum Analysis}

The biochemical effects of various doses of $\mathrm{MgO}$ nanoparticles, as shown in Table 2 and Figure 3, including on aspartate aminotransferase, alanine aminotransferase, alkaline phosphatase, $\gamma$-glutamyl transpeptidase, urea, and creatinine were investigated. It was found that the level of AST and ALP are significantly increased in the higher than 
125 and $250 \mu \mathrm{g} \cdot \mathrm{mL}^{-1}$, respectively, but the level of ALT, GGT, urea, and creatinine, showed no significant change for any dose of particles.

\subsection{Histopathological Research}

In order to assess the toxicity of $\mathrm{MgO}$ nanoparticles, histological analysis was done on liver and kidney. The results are shown in Figure 4. The liver of the control rats showed normal hepatic architecture, portal triad, and central vein (Fig. 4A, C, and E). The $\mathrm{MgO}$ nanoparticles treated rats revealed some changes in the liver mainly at the highest concentration.
The histopathological changes of the livers are proliferation of bile ductules (Fig. 4B, D). In some regions of the liver sinusoids, a congestion was found (Fig. 4F), which showed that $\mathrm{MgO}$ nanoparticles induced inflammation in liver tissues. Exposure to these particles also caused apoptotic cells (probably) around the portal triad (Fig. 4D).

The $\mathrm{MgO}$ nanoparticles treated kidney by various doses did not exhibit any degenerative effects in the cells (Fig. 4G, H).

Table 1. Hematological analysis revealing the toxic effect of $\mathrm{MgO}$ nanoparticles in rats based on $\mu \mathrm{g} \cdot \mathrm{mL}^{-1}$.

\begin{tabular}{lccccc}
\hline Parameters & Control & $\mathbf{6 2 . 5}$ & $\mathbf{1 2 5}$ & $\mathbf{2 5 0}$ & $\mathbf{5 0 0}$ \\
\hline Hb $(\mathbf{g} / \mathbf{d l})$ & $13.96 \pm 0.38$ & $13.96 \pm 0.26$ & $14.07 \pm 0.41$ & $14.01 \pm 0.41$ & $8.10 \pm 0.23$ \\
RBC $\left(\times \mathbf{1 0}^{6} / \boldsymbol{\mu l}\right)$ & $7.93 \pm 0.39$ & $8.02 \pm 0.44$ & $8.22 \pm 0.28$ & $5.10 \pm 0.77^{*}$ \\
MCV $(\mathbf{f l})$ & $51.02 \pm 1.68$ & $50.37 \pm 0.74$ & $50.30 \pm 0.80$ & $50.58 \pm 3.41$ & $51.20 \pm 3.04$ \\
MCH $(\mathbf{p g})$ & $17.03 \pm 0.60$ & $16.86 \pm 0.38$ & $16.90 \pm 0.27$ & $17.11 \pm 0.65$ & $17.44 \pm 0.85$ \\
MCHC $(\mathbf{g} / \mathbf{d l})$ & $33.37 \pm 0.89$ & $32.79 \pm 1.20$ & $33.71 \pm 1.11$ & $32.60 \pm 0.87$ & $32.91 \pm 1.28$ \\
PLT $\left(\times \mathbf{1 0}^{3} / \boldsymbol{\mu l}\right)$ & $627.43 \pm 47.55$ & $619.86 \pm 70.16$ & $617.71 \pm 27.75$ & $591.43 \pm 80.90$ & $604.71 \pm 92.46$ \\
HCT $(\%)$ & $41.24 \pm 0.83$ & $41.27 \pm 0.39$ & $41.80 \pm 0.82$ & $42.74 \pm 1.63$ & $46.20 \pm 1.80^{*}$ \\
WBC $\left(\times \mathbf{1 0}^{3} / \boldsymbol{\mu l}\right)$ & $6.8 \pm 0.47$ & $6.97 \pm 0.38$ & $7.54 \pm 0.73$ & $9.84 \pm 1.72^{*}$ & $12.46 \pm 2.10^{*}$ \\
\hline
\end{tabular}

Bars represent mean \pm standard deviation of $\mathrm{n}=7$; Hb, Hemoglobin; RBC, Red Blood Cells; MCV, mean Corpuscular Volume; MCH, Mean Corpuscular Hemoglobin; MCHC, mean corpuscular hemoglobin concentration; PLT, platelet count; HCT, hematocrit; WBC, white blood cells. Data were analyzed using One Way ANOVA followed by Tukey HSD Test. ${ }^{*}$ Represents significant difference from the Control Group $(\mathrm{P}<0.05)$.

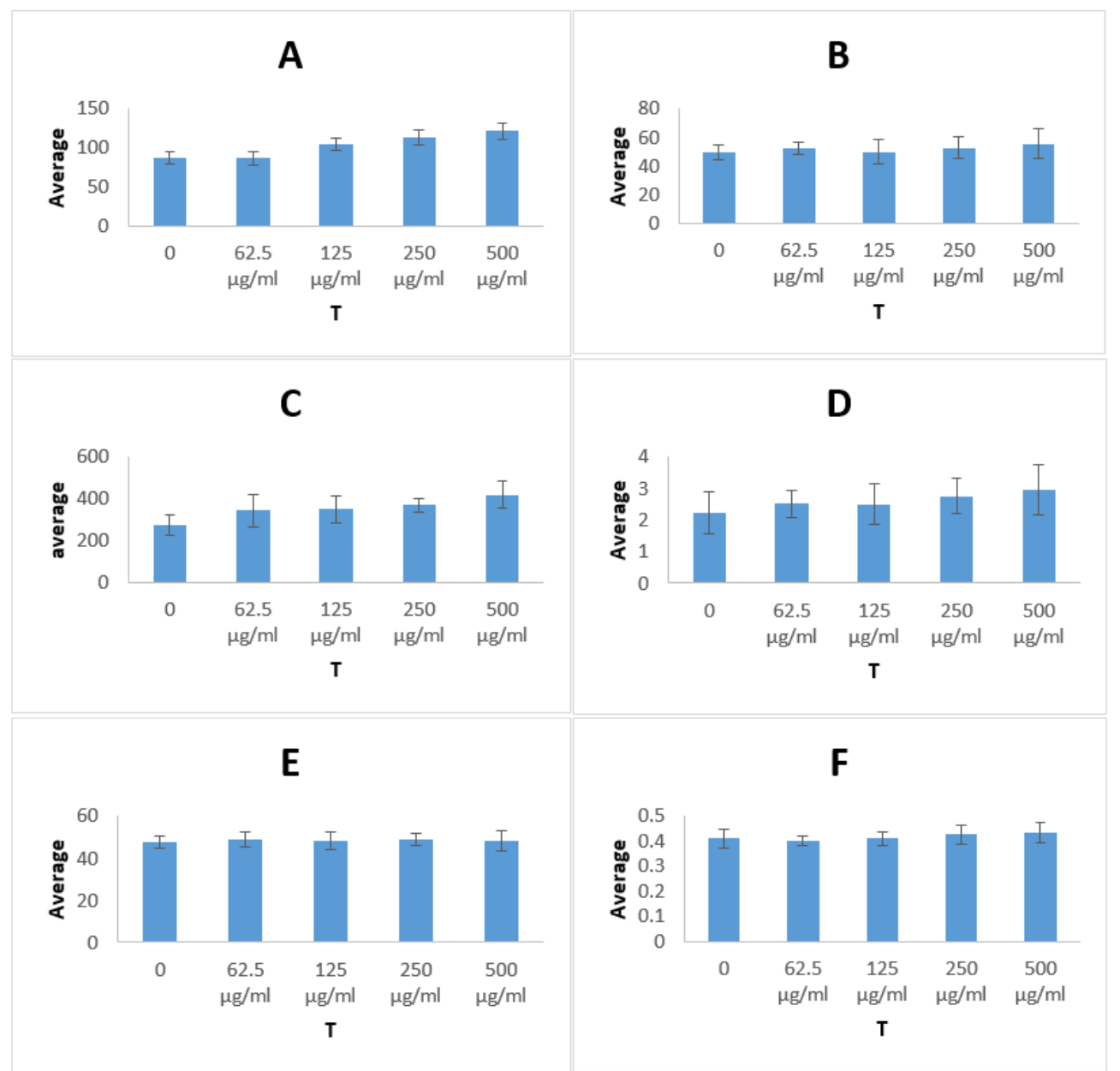

Figure 3. The biochemical results for rats treated with $\mathrm{MgO}$ nanoparticles 28 days after intraperitoneal injection at a different concentrations (62.5-500 $\mu \mathrm{g} . \mathrm{mL}^{-1}$ ). These results show mean and standard diviations of: (A) aspartate transaminase; (B) alanine transaminase; (C) alkalin phosphatase; (D) $\gamma$ glutamyl transpeptidase; (E) urea; (F) creatinine. Abbreviations: AST, aspartate transaminase; ALT, alanine transaminase; ALP, alkaline phosphatase; GGT, $\gamma$-glutamyl transpeptidase; UREA, urea; CREA, creatinine 
Table 2. Biochemical analysis metabolic enzymes and renal function after intraperitoneal injection of different doses (62.5-500 $\mu$ g.mL-1) for 28 days (every other day).

\begin{tabular}{lcccccc}
\hline Groups & AST & ALT & ALP & GGT & UREA & CREA \\
\hline Control & $86.79 \pm 8.27$ & $49.93 \pm 5.51$ & $274.71 \pm 49.35$ & $2.23 \pm 0.71$ & $47.68 \pm 3.29$ & $0.41 \pm 0.38$ \\
$\mathbf{6 2 . 5}(\boldsymbol{\mu g} / \mathbf{m l})$ & $86.29 \pm 9.79$ & $52.29 \pm 4.78$ & $342.71 \pm 79.32$ & $2.52 \pm 0.45$ & $48.94 \pm 3.77$ & $0.40 \pm 0.19$ \\
$\mathbf{1 2 5}(\boldsymbol{\mu g} / \mathbf{m l})$ & $105.00 \pm 7.80^{*}$ & $49.79 \pm 8.74$ & $351.14 \pm 68.22$ & $2.50 \pm 0.69$ & $48.10 \pm 4.34$ & $0.41 \pm 0.26$ \\
$\mathbf{2 5 0}(\boldsymbol{\mu g} / \mathbf{m l})$ & $113.71 \pm 9.66^{*}$ & $52.50 \pm 7.97$ & $396.43 \pm 33.04^{*}$ & $2.76 \pm 0.58$ & $49.03 \pm 3.15$ & $0.43 \pm 0.41$ \\
$\mathbf{5 0 0}(\boldsymbol{\mu g} / \mathbf{m l})$ & $121.14 \pm 10.82^{*}$ & $55.71 \pm 10.84$ & $419.14 \pm 65.71^{*}$ & $2.96 \pm 0.81$ & $48.46 \pm 5.17$ & $0.43 \pm 0.42$ \\
\hline
\end{tabular}

Bar represent mean \pm standard deviation of $\mathrm{n}=7$. Data were analyzed using one way ANOVA followed by Tukey HSD test. ${ }^{*}$ Represents significant difference from the control group $(\mathrm{P}<0.05)$. All the values of AST, ALT, ALP and GGT are expressed as $\mathrm{U}^{-1} \mathrm{~L}^{-1}$, also Urea and Creatinine in mg.dL ${ }^{-1}$.

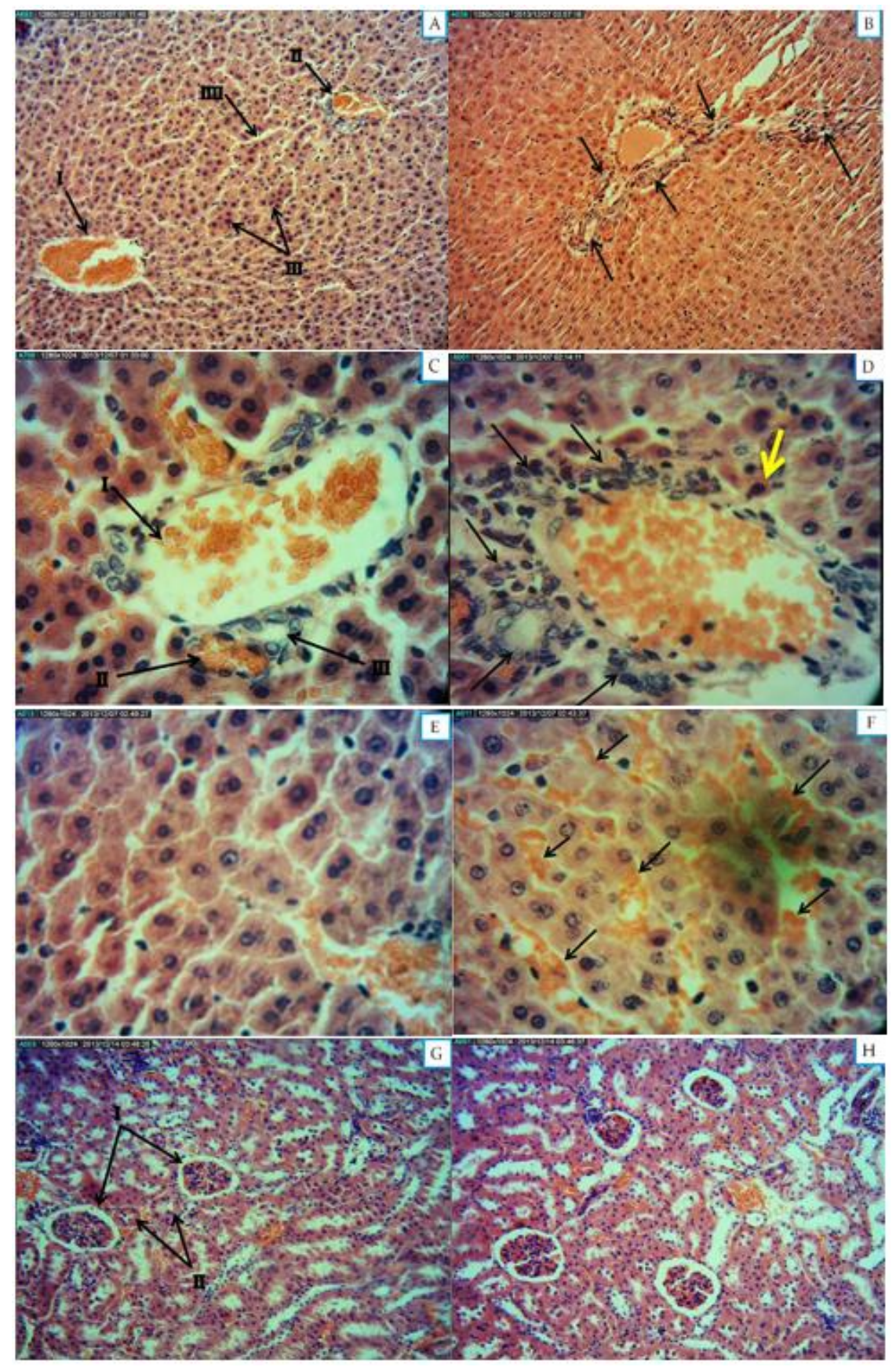

Figure 4. Toxicity studies of $\mathrm{MgO}$ nanoparticles in rat organs. Histological specimens of rat tissues (liver and kidney) collected from rats euthanized on day 28, stained with hematoxylin and eosin ( $\mathrm{H}$ and $\mathrm{E}$ ) showed normal histology, $\mathrm{n}=7$ for each group. A. Control animal liver section showing normal central vein (I), portal triad (II), hepatocytic architecture (III) and liver sinusoids (IIII); B. MgO nanoparticles at a dose of $500 \mu \mathrm{gg} \cdot \mathrm{mL}^{-1}$ treated liver showing proliferation of bile ductules; C. Control liver section showing normal hepatic artery (I), portal vein (II), and bile duct (III); D. MgO nanoparticles at a dose of $500 \mu \mathrm{g} . \mathrm{mL}^{-1}$ treated liver showing proliferation of bile ductules and apoptotic cell (probably); E. Control liver section showing normal liver sinusoids; F. MgO nanoparticles at a dose of $500 \mu \mathrm{g} \cdot \mathrm{mL}^{-1}$ treated liver showing Congestion in some regions of the liver sinusoids; G. Control kidney section showing normal corpuscle (I), and tubules structure (II); H. MgO nanoparticles at a dose of $500 \mu \mathrm{g} \cdot \mathrm{mL}^{-1}$ treated kidney also showed normal structure similar with control group. 


\section{Discussion}

The aim of this study was to survey the toxicity effect of $\mathrm{MgO}$ nanoparticles on animal model. For this purpose, estimation of hematology and biochemistry is very useful (28). The results of the present study indicated that white blood cells, hemoglobin, red blood cells, and hematocrit were increased with the injection of $\mathrm{MgO}$ nanoparticles doses of 250 and $500 \mu \mathrm{g} \cdot \mathrm{mL}^{-1}$.

As for rats, their white blood cells are found to be susceptible to physiological responses. Hauck et al., suggested that rising white blood cells in the rats treated with quantum-dot can be recognized as an inflammatory response (29). Additionally, red blood cells are obtained from hematopoietic stem cells mostly in the marrow bones. After a series of puberty steps and mainly upon hormone erythropoietin, red blood cells enucleate and enter through circulation system. Thus, all changes in red blood cell levels may be associated with the hematopoietic system (26). Any elevation in red blood cells as it can be seen in rats treated with $\mathrm{MgO}$ nanoparticles suggesting that size particles $(10-15 \mathrm{~nm})$ and dose $\left(500 \mu \mathrm{g} . \mathrm{mL}^{-1}\right)$ affect the hematopoietic system. Thus, nanoparticles are able to trigger an inflammatory response, and in addition increases or decreases immune system function, and simultaneously alters related hematologic factors including blood cell counts $(29,30)$. It can be noted, the higher dose of $\mathrm{MgO}$ nanoparticles, the more hematologic factors will be affected.

In this research, findings demonstrated that injection of $\mathrm{MgO}$ nanoparticles to Wistar rats induces an increase in the level of markers of liver function such as AST and ALP. In return, injected with $\mathrm{MgO}$ nanoparticles in rats no change was observed on serum levels of ALT and GGT as well as renal function. Aspartate aminotransferase and alanine aminotransferase activities have been considered as criteria for hepatocellular damage since 1955. Eighty percent of AST in hepatocytes is in mitochondria, whereas ALT is located elsewhere in the cytoplasm. The various intracellular locations of these enzymes have led to observations and speculations about their role in the diagnosis and prognosis of liver disease (31). Results showed that injection of $\mathrm{MgO}$ nanoparticles induces concentration-related increases in AST, but does not alter the levels of ALT. Previous research has reported that the ratio of AST: ALT, or De Ritis quotient, which normally is 1 or more, is at 3-4:1 in alcoholic liver disease, while the ALT level hovers around normal. The exact reason for this is unknown, though two possible explanations are available: 1 ) alcohol is a mitochondrial toxin, and 2) pyridoxine is deficient in alcoholics. Pyridoxal 5'-phosphate deficiency is rate limiting in the assay for ALT (32). As shown above, it seems that $\mathrm{MgO}$ nanoparticles are mitochondrial toxins like alcohol and because of the further presence of these enzymes in the mitochondria, with increasing the dose-dependent concentration of $\mathrm{MgO}$ nanoparticles, the amount of AST in serum will also increase.

ALP is also called cholestatic liver enzymes. Cholestasis is a condition that causes partial or thorough occlusion of the bile ducts (33). If the bile duct is fervent or defective, ALP can get backed up and spill out from the liver into the bloodstream. (34). Therefore, the release of ALP in serum by administration of $\mathrm{MgO}$ nanoparticles at doses of 250 and $500 \mu \mathrm{g} \cdot \mathrm{mL}^{-1}$ in connection with inflammation of bile ductules, may be predicted. In addition, the levels of urea and creatinine in rat's blood serum were tested as a measure of kidney function. When the serum creatinine and urea are significantly higher than normal, kidney function is seriously damaged (35).

A detailed analysis of these metabolites in serum of animals treated with various doses of $\mathrm{MgO}$ nanoparticles as compared to the controls showed no statistically significant differences in any of the tested parameters. Histopathological examinations in the rat's liver showed proliferation of bile ductules, congestion in some regions of the liver sinusoids, and apoptotic cells (probably) in high-dose groups, but no histological changes were found in the kidney functions. New studies on cholestatic liver disorders showed the contributions of resident macrophages in the liver, kupffer cells, as well as pathogenesis of a sustained inflammatory response following apoptotic cell death (36).

On the basis of the histological results, it seems that variations in liver tissue including proliferation of bile ductules, sinusoidal dilatation and congestion (SDC), accompanied by elevated ALP in the long term, may lead to chronic biliary disease. The authors proved that venous outflow impairment leads to sinusoidal dilatation and congestion (SDC) in the liver biopsy (37, 38). Liver biopsies of patients with venous outflow impairment exhibited bile ductular proliferation, portal inflammations and portal-based fibrosis as well as elevated ALP and GGT this ultimately will have resulted in suspicion of chronic biliary disease (39).

The results of Gelli et al., showed that a dose-dependent pulmonary toxicity in rats and various tissue damage markers, like alkaline phosphatase (ALP) and lactate dehydrogenase $(\mathrm{LDH})$, in Broncho alveolar lavage (BAL) fluid and histopathology of lungs at 1, 7, and 30 days of post-exposure intervals was generated by $\mathrm{MgO}$ nanoparticles exposed via intra-tracheal instillation at the doses of $1 \mathrm{mg} / \mathrm{kg}$ or $5 \mathrm{mg} / \mathrm{kg}$ into rat lung (40). The results of Mangalampalli et al., indicated that the induced significant DNA damage and aberrations in chromosomes after 28 day repeated oral administration in Wistar rats was induced by the MgO NPs with three different doses (250, 500, and $1000 \mathrm{mg} / \mathrm{kg}$ ). Biochemical and genotoxic parameters in dose- 
dependent and gender-independent manner were improved by the oral administration of MgO NPs (41). In a research performed by Lasagna-Reeves et al. on bioaccumulation and toxicity of gold nanoparticles, it was found that exposing to repeated injection of gold nanoparticles was led to significant increase in the amount of gold in kidneys. Substantially, the higher gold nanoparticles dose, the smaller the percentage of gold accumulated was found, showing effective removal of gold nanoparticles from the body (42). Experimental results of Chen et al. also showed that injection of titanium dioxide $\left(\mathrm{TiO}_{2}\right)$ nanoparticles with various doses $\left(0,324,648,972,1296,1944\right.$ or 2592 mg.kg $\left.{ }^{-1}\right)$ induced relatively higher ALT and AST levels in treated mice in comparison to the control group, whereas the differences in BUN value between experimental groups and the control group were not evident. It can suggest that $\mathrm{TiO}_{2}$ nanoparticles had a stronger toxicity to liver than to kidney (43). As a whole, considering her disability of the experimental results, it can be seen that administration of 10-15 nm MgO nanoparticles at doses of 250 and $500 \mu \mathrm{g} . \mathrm{mL}^{-1}$ can cause obvious adverse effects on liver function and indicates an inflammatory response.

Subsequently, treatment with low concentrations of $\mathrm{MgO}$ nanoparticles (62.5 and $125 \mu \mathrm{g} \cdot \mathrm{mL}^{-1}$ ) did not induce any apparent toxicity in the rats during the study period. The present results are in good agreements with the results of Ge et al., showed low concentration (below $200 \mu \mathrm{g} \cdot \mathrm{mL}^{-1}$ ) of $\mathrm{MgO}$ nanoparticles suspension no cytotoxicity on human umbilical vein endothelial cells (HUVECs) in vitro. Nonetheless, when these particles concentrations go up to $500 \mu \mathrm{g} \cdot \mathrm{mL}^{-1}$, the relative growth rate will be lower than the control (44). Investigation of antioxidants in rat serum after exposure to magnesium oxide $(\mathrm{MgO})$ nanoparticles revealed that instillations of $\mathrm{MgO}$ (at a dose of 1 and $5 \mathrm{mg} \cdot \mathrm{kg}^{-1}$ of body weight) induces oxidative stress by reducing the total antioxidant capacity in rats. Findings of recent studies suggest potentially undesirable effects of these particles in chronic exposures (45).

Experimental data in association with influence on cell viability and oxidative stress together with physical and chemical characterizations of industrial metal oxide nanoparticles showed the major cytotoxic agent of these particles such as $\mathrm{MgO}$ was metal ion release (46). Patel Manoj $\mathrm{K}$ et al., indicated that $\mathrm{MgO}$ nanoparticles are appropriate for anti-cancer activities. In this paper, human intestinal cell lines (INT 407) and human cervical cancer cell lines ( $\mathrm{SiHa}$ ) were examined for cytotoxic assay of $\mathrm{MgO}$ nanoparticles in the range of $0_{-}$ $350 \mu \mathrm{g} \cdot \mathrm{mL}^{-1}$. Results showed that in low concentrations (below $300 \mu \mathrm{g} \cdot \mathrm{mL}^{-1}$ ). No significant cytotoxicity was found in Human intestinal and cancerous cells but when the concentration of $\mathrm{MgO}$ nanoparticles was increased to above $300 \mu \mathrm{g} \cdot \mathrm{mL}^{-1}$, the comparative growth rate in cancerous cells was lower than the control (47). In accordance with previous in vitro findings and in vivo toxicity investigation, authors declare that $\mathrm{MgO}$ nanoparticles at concentrations lower than $250 \mu \mathrm{g} \cdot \mathrm{mL}^{-1}$ are found to be safe. Therefore, it is viable to use these particles for water purification, encapsulate drugs for utilization in the clinical setting, and other desired applications.

\section{Acknowledgments}

The author's special thanks goes to Dr. Abbasali Palizban from Isfahan University of Medical Sciences for his precious comments and assistance on this manuscript.

\section{References}

1. Medina C, Santos-Martinez MJ, Radomski A, Corrigan OI, Radomski MW. Nanoparticles: pharmacological and toxicological significance. $\mathrm{Br} J$ Pharmacol. 2007;150(5):552-558. doi: 10.1038/sj.bjp.0707130 pmid: 17245366

2. Gajjar P, Pettee B, Britt DW, Huang W, Johnson WP, Anderson AJ. Antimicrobial activities of commercial nanoparticles against an environmental soil microbe, Pseudomonas putida KT2440. J Biol Eng. 2009;3(1):9. doi: 10.1186/1754-1611-3-9 pmid: 19558688

3. Stoimenov PK, Klinger RL, Marchin GL, Klabunde KJ. Metal Oxide Nanoparticles as Bactericidal Agents. Langmuir. 2002;18(17):6679-6686. doi: 10.1021/la0 202374

4. Gupta VK, Ali I, Saleh TA, Nayak A, Agarwal S. Chemical treatment technologies for waste-water recycling-an overview. RSC Adv. 2012;2(16):6380. doi: 10.1039/c2ra20340e

5. Qu X, Brame J, Li Q, Alvarez PJ. Nanotechnology for a safe and sustainable water supply: enabling integrated water treatment and reuse. Acc Chem Res. 2013;46(3):834-843. doi: 10.1021/ar300029v pmid: 22738389

6. Sawai J, Kojima H, Igarashi H, Hashimoto A, Shoji S, Takehara A, et al. Escherichia coli damage by ceramic powder slurries. J Chem Eng Japan. 1997;30(6):10341039. doi: 10.1252 /jcej.30.1034

7. Donaldson K, Aitken R, Tran L, Stone V, Duffin R, Forrest $\mathrm{G}$, et al. Carbon nanotubes: a review of their properties in relation to pulmonary toxicology and workplace safety. Toxicol Sci. 2006;92(1):5-22. doi: 10.1093/toxsci/kfj130 pmid: 16484287

8. Saleem K, A. Wani W, Haque A, Milhotra A, Ali I. Nanodrugs: Magic Bullets in Cancer Chemotherapy: Bentham Science 2013. 437-494 p.

9. Ali I, Rahis U, Salim K, Rather MA, Wani WA, Haque A. Advances in nano drugs for cancer chemotherapy. Curr Cancer Drug Targets. 2011;11(2):135-146. doi: 10.2174/156800911794328493 pmid: 21158724

10. Ali I. Editorial [Hot Topic: Nano Drugs: Novel Agents for Cancer Chemo-Therapy (Guest Editor: Imran Ali)]2011. 130-130 p.

11. Bertinetti L, Drouet C, Combes C, Rey C, Tampieri A, Coluccia $S$, et al. Surface characteristics of nanocrystalline apatites: effect of $\mathrm{mg}$ surface enrichment on morphology, surface hydration species, and cationic environments. Langmuir. 
2009;25(10):5647-5654. doi: 10.1021/la804230j pmid: 19281274

12. Martinez-Boubeta C, Balcells L, Cristofol R, Sanfeliu C, Rodriguez E, Weissleder R, et al. Self-assembled multifunctional $\mathrm{Fe} / \mathrm{MgO}$ nanospheres for magnetic resonance imaging and hyperthermia. Nanomedicine. 2010;6(2):362-370. doi: 10.1016/j.nano.2009.09.003 pmid: 19800988

13. Di DR, He ZZ, Sun ZQ Liu J. A new nano-cryosurgical modality for tumor treatment using biodegradable $\mathrm{MgO}$ nanoparticles. Nanomedicine. 2012;8(8):12331241. doi: $10.1016 /$ j.nano.2012.02.010 pmid: 22406 189

14. Koper OB, Klabunde JS, Marchin GL, Klabunde KJ, Stoimenov P, Bohra L. Nanoscale powders and formulations with biocidal activity toward spores and vegetative cells of bacillus species, viruses, and toxins. Curr Microbiol. 2002;44(1):49-55. doi: 10.1007/s00284-001-0073-x pmid: 11727041

15. Krishnamoorthy K, Moon JY, Hyun HB, Cho SK, Kim S-J. Mechanistic investigation on the toxicity of $\mathrm{MgO}$ nanoparticles toward cancer cells. J Mater Chem. 2012;22 (47):24610. doi: 10.1039/c2jm35087d

16. Hasbullah NI, Mazatulikhma MZ, Kamarulzaman N. Nanotoxicity of Magnesium Oxide on Human Neuroblastoma SH-SY5Y Cell Lines. Adv Mater Res. 2013;667:160-164. doi: 10.4028/www.scientific.net/A MR.667.160

17. Canesi L, Ciacci C, Betti M, Fabbri R, Canonico B, Fantinati A, et al. Immunotoxicity of carbon black nanoparticles to blue mussel hemocytes. Environ Int. 2008;34(8):1114-1119. doi: 10.1016/j.envint.2008.04 .002 pmid: 18486973

18. Finney LA, O'Halloran TV. Transition metal speciation in the cell: insights from the chemistry of metal ion receptors. Science. 2003;300(5621):931-936. doi: 10.1126/science. 1085049 pmid: 12738850

19. Nel A, Xia T, Madler L, Li N. Toxic potential of materials at the nanolevel. Science. 2006;311(5761):622-627. doi: 10.1126/science.11143 97 pmid: 16456071

20. Chen Z, Meng H, Xing G, Chen C, Zhao Y, Jia G, et al. Acute toxicological effects of copper nanoparticles in vivo. Toxicol Lett. 2006;163(2):109-120. doi: 10.1016/j.toxlet.2005.10.003 pmid: 16289865

21. Cho EC, Au L, Zhang Q Xia Y. The effects of size, shape, and surface functional group of gold nanostructures on their adsorption and internalization by cells. Small. 2010;6(4):517-522. doi: 10.1002/smll.200901622 pmid: 20029850

22. Sayes CM, Reed KL, Warheit DB. Assessing toxicity of fine and nanoparticles: comparing in vitro measurements to in vivo pulmonary toxicity profiles. Toxicol Sci. 2007;97(1):163-180. doi: 10.1093/toxs ci/kfm018 pmid: 17301066

23. Kim JS, Yoon TJ, Yu KN, Kim BG, Park SJ, Kim HW, et al. Toxicity and tissue distribution of magnetic nanoparticles in mice. Toxicol Sci.2006;89(1):338-347. doi: $10.1093 /$ toxsci/kfj027 pmid: 16237191

24. Yang ST, Fernando KA, Liu JH, Wang J, Sun HF, Liu Y, et al. Covalently PEGylated carbon nanotubes with stealth character in vivo. Small. 2008;4(7):940-944. doi: 10.1002/smll.200700714 pmid: 18574799
25. Lai JC, Lai MB, Jandhyam S, Dukhande VV, Bhushan A, Daniels CK, et al. Exposure to titanium dioxide and other metallic oxide nanoparticles induces cytotoxicity on human neural cells and fibroblasts. Int $J$ Nanomedicine. 2008;3(4):533-545. doi: 10.2147/ijn.s 3234 pmid: 19337421

26. Zhang XD, Wu D, Shen X, Liu PX, Yang N, Zhao B, et al. Size-dependent in vivo toxicity of PEG-coated gold nanoparticles. Int J Nanomedicine. 2011;6:2071-2081. doi: 10.2147/IJN.S21657 pmid: 21976982

27. Demirag K, Cankayali I, Eris O, Moral AR, Pehlivan M. The comparison of therapeutic effects of atropine and pralidoxime on cardiac signs in rats with experimental organophosphate poisoning. Adv Ther. 2005;22(2):7986. pmid: 16020398

28. Sadauskas E, Danscher G, Stoltenberg M, Vogel U, Larsen A, Wallin H. Protracted elimination of gold nanoparticles from mouse liver. Nanomedicine. 2009;5(2):162-169. doi: 10.1016/j.nano.2008.11.002 pmid: 19217434

29. Hauck TS, Anderson RE, Fischer HC, Newbigging S, Chan WC. In vivo quantum-dot toxicity assessment. Small. 2010;6(1):138-144. doi: 10.1002/smll.200900 626 pmid: 19743433

30. Gjetting T, Arildsen NS, Christensen CL, Poulsen TT, Roth JA, Handlos VN, et al. In vitro and in vivo effects of polyethylene glycol (PEG)-modified lipid in DOTAP/cholesterol-mediated gene transfection. Int $J$ Nanomedicine. 2010;5:371-383. doi: 10.2147/ijn.s104 62 pmid: 20957159

31. Nalpas B, Vassault A, Charpin S, Lacour B, Berthelot P. Serum mitochondrial aspartate aminotransferase as a marker of chronic alcoholism: diagnostic value and interpretation in a liver unit. Hepatology. 1986;6(4):608-614. doi: 10.1002/hep.1840060410 pmid: 3732996

32. Vanderlinde RE. Review of pyridoxal phosphate and the transaminases in liver disease. Ann Clin Lab Sci. 1986;16(2):79-93. pmid: 3008634

33. Popper H. Cholestasis. Annu Rev Med. 1968;19(1):3956. doi: 10.1146/annurev.me.19.020168.000351 pmid: 4871695

34. Mukherjee P, Bhattacharya R, Wang P, Wang L, Basu S, Nagy JA, et al. Antiangiogenic properties of gold nanoparticles. Clin Cancer Res. 2005;11 (9):3530-3534. doi: 10.1158/1078-0432.CCR-04-2482 pmid: 158672 56

35. Abdelhalim MA, Abdelmottaleb Moussa SA. The gold nanoparticle size and exposure duration effect on the liver and kidney function of rats: In vivo. Saudi J Biol Sci. 2013;20(2):177-181. doi: 10.1016/j.sjbs.2013.01.007 pmid: 23961234

36. Canbay A, Feldstein AE, Higuchi H, Werneburg N, Grambihler A, Bronk SF, et al. Kupffer cell engulfment of apoptotic bodies stimulates death ligand and cytokine expression. Hepatology. 2003;38(5):11881198. doi: $10.1053 /$ jhep.2003.50472 pmid: 14578857

37. Valla DC. Hepatic vein thrombosis (Budd-Chiari syndrome). Semin Liver Dis. 2002;22(1):5-14. doi: 10.1055/s-2002-23202 pmid: 11928075

38. Tanaka M, Wanless IR. Pathology of the liver in BuddChiari syndrome: portal vein thrombosis and the histogenesis of veno-centric cirrhosis, veno-portal cirrhosis, and large regenerative nodules. Hepatology. 
1998;27(2):488-496. doi: 10.1002/hep.510270224 pmid: 9462648

39. Kakar S, Batts KP, Poterucha JJ, Burgart LJ. Histologic changes mimicking biliary disease in liver biopsies with venous outflow impairment. Mod Pathol. 2004;17(7):874-878. doi: 10.1038/modpathol.38000 73 pmid: 15098006

40. Gelli K, Porika M, Anreddy RN. Assessment of pulmonary toxicity of $\mathrm{MgO}$ nanoparticles in rats. Environ Toxicol. 2015;30(3):308-314. doi: 10.1002/tox.21908 pmid: 24096598

41. Mangalampalli B, Dumala N, Perumalla Venkata R, Grover P. Genotoxicity, biochemical, and biodistribution studies of magnesium oxide nano and microparticles in albino wistar rats after 28-day repeated oral exposure. Environ Toxicol. 2018;33(4):396-410. doi: $10.1002 /$ tox.22526 pmid: 29282847

42. Lasagna-Reeves C, Gonzalez-Romero D, Barria MA, Olmedo I, Clos A, Sadagopa Ramanujam VM, et al. Bioaccumulation and toxicity of gold nanoparticles after repeated administration in mice. Biochem Biophys Res Commun. 2010;393(4):649-655. doi: 10.1016/j.bbr c.2010.02.046 pmid: 20153731

43. Chen J, Dong X, Zhao J, Tang G. In vivo acute toxicity of titanium dioxide nanoparticles to mice after intraperitioneal injection. $J$ Appl Toxicol. 2009;29(4):330-337. doi: 10.1002/jat.1414 pmid: 19156710

44. Ge S, Wang G, Shen Y, Zhang Q Jia D, Wang H, et al. Cytotoxic effects of $\mathrm{MgO}$ nanoparticles on human umbilical vein endothelial cells in vitro. IET Nanobiotechnol. 2011;5(2):36. doi: 10.1049/ietnbt.2010.0022 pmid: 21495778

45. Kiranmai G, Reddy AR. Antioxidant status in $\mathrm{MgO}$ nanoparticle-exposed rats. Toxicol Ind Health. 2013;29(10):897-903. doi: 10.1177/0748233712446 723 pmid: 22673104

46. Horie M, Fujita K, Kato H, Endoh S, Nishio K, Komaba LK, et al. Association of the physical and chemical properties and the cytotoxicity of metal oxide nanoparticles: metal ion release, adsorption ability and specific surface area. Metallomics. 2012;4(4):350-360. doi: $10.1039 /$ c2mt20016c pmid: 22419205

47. Patel MK, Zafaryab M, Rizvi MMA, Agrawal VV, Ansari ZA, Malhotra BD, et al. Antibacterial and Cytotoxic Effect of Magnesium Oxide Nanoparticles on Bacterial and Human Cells. J Nanoeng Nanomanufact 2013;3(2):162-166. doi: 10.1166/jnan.2013.1122 